OPEN ACCESS

Edited by:

Nada El Darra,

Beirut Arab University, Lebanon

Reviewed by:

Armando Venâncio,

University of Minho, Portugal

Wageh Darwish

Zagazig University, Egypt

*Correspondence:

Carlotta Ceniti

ceniti@unicz.it

Nicola Costanzo

costanzo.nic@unicz.it

tThese authors have contributed equally to this work and share the first

authorship

Specialty section:

This article was submitted to

Food Chemistry,

a section of the journal

Frontiers in Nutrition

Received: 04 May 2021

Accepted: 16 August 2021

Published: 21 September 2021

Citation:

Ceniti C, Costanzo N, Spina AA, Rodolfi M, Tilocca B, Piras $C$, Britti D

and Morittu VM (2021) Fungal Contamination and Aflatoxin B1 Detected in Hay for Dairy Cows in

South Italy. Front. Nutr. 8:704976.

doi: 10.3389/fnut.2021.704976

\section{Fungal Contamination and Aflatoxin B1 Detected in Hay for Dairy Cows in South Italy}

\author{
Carlotta Ceniti ${ }^{1,2 * t}$, Nicola Costanzo ${ }^{1,2 * t}$, Anna Antonella Spina ${ }^{1,2}$, Marinella Rodolfi ${ }^{3}$, \\ Bruno Tilocca ${ }^{1,2}$, Cristian Piras ${ }^{1,2}$, Domenico Britti ${ }^{1,2}$ and Valeria Maria Morittu ${ }^{1,2}$ \\ 1 Department of Health Sciences University "Magna Græcia" of Catanzaro, Campus Universitario "Salvatore Venuta", \\ Catanzaro, Italy, ${ }^{2}$ Interdepartmental Services Centre of Veterinary for Human and Animal Health, Department of Health \\ Science, Magna Græcia University, Catanzaro, Italy, ${ }^{3}$ Department of Earth and Environmental Sciences, University of Pavia, \\ Pavia, Italy
}

The growth of filamentous fungi on fodder is recognized as responsible for fungal deterioration and mycotoxin contamination of the plant mass leads to economic losses in the dairy cow production system. Mycotoxin contamination has significant implications for human and animal health and is one of the major concerns in the food and feed chain. This research provides an insight into the variety of viable molds (i.e., filamentous microfungi) that can be isolated from hay produced in South Italy and destined to dairy cows. On different lots of hay $(n=55)$ collected from 20 dairy farms, a total of 33 different fungal species were identified. The most representative was Cladosporium cladosporioides ( $n=46,84 \%$ ) followed by Alternaria alternata ( $n=25,45 \%$ ), and Rhizopus stolonifer ( $n=24,44 \%)$. The species most closely related to aflatoxin (AF) contamination, Aspergillus flavus, was often isolated ( $n=11,20 \%)$. Regarding AF detection, all the hay samples were found to be scarcely contaminated by AFB1 and showed values from 0.0020 to $0.0077 \mathrm{mg} / \mathrm{kg}$, below the limits established by European Union (EU legislation) $(0.02 \mathrm{mg} / \mathrm{kg}$ ). None of the samples were positive for Aspergillia and tested for AFB1 showed results exceeding established limits. Additionally, hay with moisture between 15.0 and $19.2 \%$ or crude ash on dry matter content ranging from 14.0 to $15.5 \%$ reported an increased presence of AFB1 $(p<0.05)$ compared to the other samples. All the analyzed hay samples, besides the presence of molds, can be considered safe for the presence of AFB1. Prevention of mold spoilage is mandatory to reduce the exposure of humans and animals to mycotoxins.

Keywords: molds, mycotoxins, aflatoxin B1, food safety, food chain, dairy, feed, one health

\section{INTRODUCTION}

The occurrence of fungi or related mycotoxins in feed destined for animal production is one of the biggest concerns for animal and human health. The filamentous fungi found on hay belong to a wide range of fungal genera, which varies depending on many pre-harvest factors, such as the geographical location of the crop and weather conditions in the field $(1,2)$, the growing season (3), and agricultural practices, as well as the post-harvest factors, such as storage conditions $(1,4)$. It is known that the growth of filamentous fungi on fodder can cause problems related to the deterioration or contamination by mycotoxins. From this point of view, despite the mycological 
and mycotoxicological state of the forage, it is considered very important for risk assessment throughout the food chain $(3,5)$, there are few studies describing these aspects on hay (6).

Among mycotoxins, AFs represent the most important group; they are normally produced as toxic secondary metabolites mainly by two fungal species: Aspergillus flavus and Aspergillus parasiticus $(7,8)$. Aflatoxin B1 (AFB1), aflatoxin B2 (AFB2), aflatoxin G1 (AFG1), and aflatoxin G2 (AFG2) are the principal classes (9). Mycotoxins can easily enter the human food chain directly via plants products and indirectly via feed. Therefore, the occurrence of mycotoxin in feedstuff may be an important source of milk contamination and, thus, a serious hazard for human health. Aflatoxin M1 (AFM1) is a hydroxylated metabolite of AFB1 and approximately $0.5-6 \%$ of the ingested AFB1 is converted to AFM1 and secreted in milk in both humans and lactating animals (9). Several studies have reported a link between AFB1 and cancer occurrence and, according to the International Agency for Research on Cancer (IARC) (10), AFs are classified as group I or carcinogenic to humans. AFB1 is the most carcinogenic AF, and its presence in lactating animals feed could produce milk contaminated with AFM1, classified by the IARC as Group 2B, possibly carcinogenic to humans $(11,12)$. The susceptibility to AFs depends on several factors, such as age, the dose of secondary metabolites, the extent of exposure, gender, the species involved, and concomitant exposure to other hazardous toxins. The liver is the primary target organ in humans and animals, and the most common injury linked to AF exposure is hepatocellular carcinoma (HCC), although several other effects, such as reduction of immunological functions (13) are reported. Furthermore, AF contamination has a negative economic impact in terms of production loss by reducing both the animal feed intake and livestock productivity and reproductive capacity (14). To avoid the toxic effects due to AF presence, the European Union (EU) has stated maximum residue limits (MRL) for AFs both in the foods and feeds, as reported in the Regulation (EC) No 1881/2006 and its amending acts and, in the Directive 2002/32/EC (15) on undesirable substances in animal feed as amended by the Commission Regulation No $574 / 2011$ (16), respectively. In the latter is indicated an AFB1 maximum load of $0.02 \mathrm{mg} / \mathrm{kg}$ for feed materials and a limit of $0.01 \mathrm{mg} / \mathrm{kg}$ for complementary and complete feeds, with the exception of compound feeds for some animal species. In particular, in compound feeds for dairy cattle, the AFB1 limit is set at $0.005 \mathrm{mg} / \mathrm{kg}$. Less restrictive limits have been established in other countries, such as the United States, where it is established a threshold of $0.02 \mathrm{mg} / \mathrm{kg}$ in feeds and ingredients for dairy animals. The presence of mycotoxins in the feed has been widely investigated, however, the ratio between the concurrent presence of the potentially toxigenic species and of its mycotoxin still represents a critical issue deserving of attention. In this study, we report the results of mycological analysis of feed and relative occurrence of mycotoxin in feedstuff destined to the dairy animals collected in dairy farms located in the Calabria region, Italy. In addition, the influence of moisture and crude ash content of hay on AFB1 contamination was evaluated.

\section{MATERIALS AND METHODS}

This study was carried out over a 3-month autumn period, from October to December. The research activity involved 20 dairy farms randomly chosen in the Catanzaro area (Italy) among the 29-producing hay. A map describing the study area and sampling locations is shown in Figure 1. Before sampling, a questionnaire was answered by the farmers to identify how many lots of hay were stored and its characteristics, such as the botanical species and the date and site of harvesting. Further information on the agronomic data, size, number of hay bales, and the storage type was acquired.

\section{Hay Sampling}

The sampling criteria and hay sampling methods adopted for this research are those indicated in Annexes I and II of Regulation (EU) no. 691/2013, which amended Regulation (EC) no. 152/2009 concerning sampling and analysis methods for official feed controls. Briefly, for each lot, an aggregate sample of about $1 \mathrm{~kg}$ was obtained by sampling a minimum of 15 bales per lot randomly chosen, using a motorized corer (length $60.0 \mathrm{~cm}$, internal diameter $22 \mathrm{~mm}$ ). The sampling devices were thoroughly sterilized before sampling a new lot of hay. After collection, the aggregate samples were transported at room temperature to the laboratory and were carefully mixed and separated in two aliquots of 700 and $300 \mathrm{~g}$ for chemical and microbiological-toxicological analysis, respectively. In this latter case, the samples were stored at $-20^{\circ} \mathrm{C}$ prior to the subsampling for the conventional mycological and mycotoxin analyses.

\section{Moisture and Crude Ash Determination}

Moisture and crude ash content of the hay samples were determined as described by AOAC (Presidential Task Force on Best Practices for Microbiological Methodology) procedures (17). Briefly, the samples were ground by a Retsch SM 100 cutting mill equipped with a bottom sieve with an aperture size of $1.0 \mathrm{~mm}$ (Retsch $\mathrm{GmbH}, 42781$ Haan, Germany), then, $5 \mathrm{~g}$ of hay were dried using the oven at $103^{\circ} \mathrm{C}$ for $4 \mathrm{~h}$ for the moisture content determination. The ash content was determined by muffle-furnace incineration of $5 \mathrm{~g}$ of the sample at $550^{\circ} \mathrm{C}$ for $3 \mathrm{~h}$. The duplicate analyses were performed on each sample.

\section{AFB1 Determination}

Determination of AFB1 in feed was conducted using the "Afla $\mathrm{B}_{1}$ ” ELISA kit (Tecna S.r.l., Italy) that has detection limits ranging from 1 to $40 \mathrm{ppb}$ equivalent to $0.001-0.040 \mathrm{mg} / \mathrm{kg}$. According to manufacturing instruction, specificity was $100 \%$ for AfB1, $5 \% \pm$ 1 for AfB2, 19\% for AfG1, and $<1$ for the AfG2. The relative SD of reproducibility was $6 \%$. A subsample of $5.0 \pm 0.1 \mathrm{~g}$ was used for the analysis: $25 \mathrm{ml}$ of a 70:30 MeOH and $\mathrm{H}_{2} \mathrm{O}$ solution were added to the sample and then, filtered through Whatman $1 \mathrm{~h}$ before analysis. Briefly, $50 \mu \mathrm{l}$ of the methanolic extract, dilution, or standard was mixed with $100 \mu$ l of conjugate directly in the dilution microliter wells. A $100 \mu \mathrm{l}$ aliquot of this mixture was added to antibody-linked wells and incubated for $10 \mathrm{~min}$ at room temperature. Finally, $100 \mathrm{ml}$ of stop solution was added and was left to stand for $5 \mathrm{~min}$ at standard temperature and pressure. The 


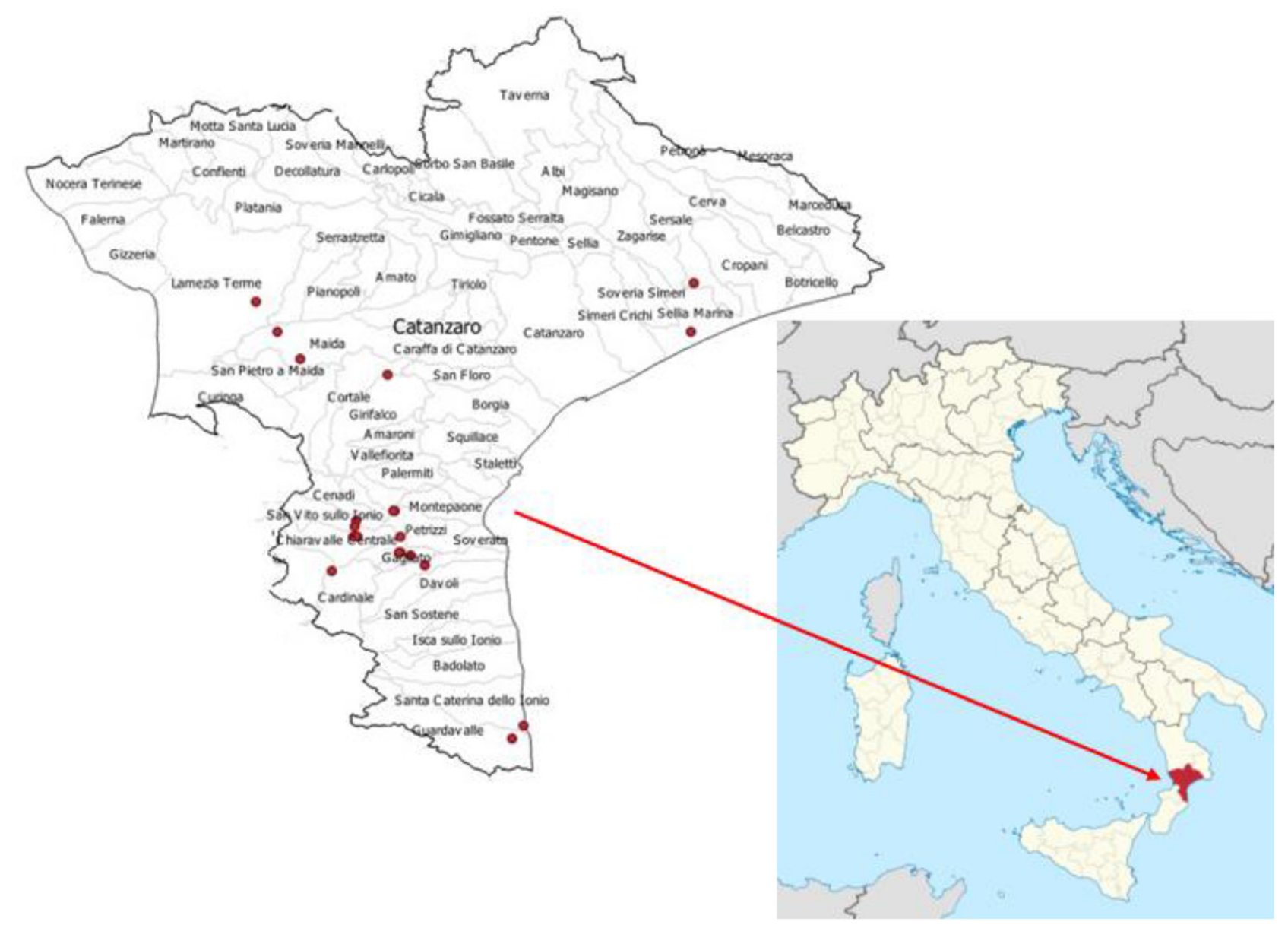

FIGURE 1 | Map of the study area and sampling locations. The lower right image shows the Italian peninsula and the Calabria region (in red). The image on the left, on the other hand, shows the places (red dots) where the farms are located, and the hay samples were taken.

absorbance measurements were performed immediately at the wavelength of $450 \mathrm{~nm}$ using a SynergyTM Biotek HT microplate reader and the Gen 5TM software (BioTek Instruments Inc., Winooski, VT, USA).

\section{Mycological Analysis}

The mycological investigation focused on the taxonomical identification of filamentous microfungi and was carried out by means of the moist chamber (MC) method. For each sample, $50 \mathrm{~g}$ of hay has been briefly washed under running tap water $(30 \mathrm{~s})$ to remove the extraneous propagules, then, drained and aseptically cut into fragments of about $1 \mathrm{~cm}$ length. The fragments were placed onto $150 \mathrm{~mm}$ Petri dishes containing a layer of Tap Water Agar (TWA, substratum composition: microbiological agar $15 \mathrm{~g}$, tap water $1,000 \mathrm{ml}$ ). This methodological approach, providing only humidity, is particularly useful to stimulate the sporulation of fungi (development of both the asexual and sexual fruiting structures and spores). In particular, it promotes the growth of both the fungal pathogens, which use the plant material as a food base and the fungal saprophytes $(18,19)$. The dishes were kept at room temperature in natural day/night conditions for 14 days and constantly observed by means of a stereomicroscope (x5). From the third day, different microfungal fruiting structures emerged from vegetal tissues. Most of them, checked at high magnification (40-x 100), were directly identified at the genus level. All the different colonies were isolated into tubes containing the generic for fungi PDA medium (Potato Dextrose Agar, SigmaAldrich, final pH $5.6 \pm 0.2$ ), then, adequately transferred and manipulated for their complete identification, according to the related taxonomical keys (20-24). Only for the strains belonging to Penicillium and Trichoderma genera, identification was limited to the genus level (molecular approaches are required to obtain a fully reliable characterization of this kind of taxa). Moreover, although yeasts were not the object of the study, some strains have been detected from various samples; their presence has been however reported, with the meaning of delineating the total microfungal (both filamentous and unicellular) colonization of hay. Finally, taxa were discussed based on their origin and their toxigenic or pathogenic potential.

\section{STATISTICAL ANALYSIS}

Mann-Witney test of GraphPad Prism version 8.3.0 for Windows (GraphPad Software, San Diego, CA, USA, www.graphpad.com) 
was used to compare the AFB1 levels of groups having different content of moisture and ash. A statistical significance was stated for $p<0.05$.

\section{RESULTS AND DISCUSSION}

In this study, we report the first insight on the microfungal occurrence and AFB1 in hay collected in South Italy. Table 1 shows the moisture and crude ash values of the hay samples. The average moisture value was $12.21 \pm 2.89 \%$. The highest moisture content was $19.21 \%$ while the lowest was $7.27 \%$. Although it is difficult to predict the moisture content for safe hay storage, Wittemberg et al. (25) reported that in alfalfa hay, moisture content of $17.5-21.6 \%$ is correlated with no mycelial development and very low sporulation. This would indicate a reduced risk even of the fungal metabolic activity in all the 55 samples considered, always taking into account that toxigenic molds can be strongly influenced by other modulating parameters, such as $\mathrm{pH}$, temperature, and light during the storage (26). Gregory et al. (26) found that hays having $16 \%$ of moisture at bailing showed little heating and contained a small but diverse microbiota, resulting in good quality. On the contrary, the wetter hay bales contained many spore-forming bacteria but few fungi, surrounded by a layer of moldy hay on the surface (26). Other researchers $(27,28)$ have established an even stricter threshold for the moisture value of safe storage of hay, namely $15 \%$ as stated by Martinson et al. (28) for Orchardgrass hay storage with low microbial activity and absence of mold.

The moisture values of the hay samples in this study fully comply with this threshold value, except for seven samples, having moisture content above 15\% (sample $n 14,15,23,24,36$, 48, and 49 in Table 1). Although, as discussed below, none of the hay samples exceeded the AFB1 tolerated content in the samples with high moisture content, it was found an AFB1 level (0.0036 $\pm 0.00031 \mathrm{mg} / \mathrm{kg})$ higher $(p=0.0428)$ than in the hays having moisture $<15 \%(0.0032 \pm 0.00096 \mathrm{mg} / \mathrm{kg})$.

For crude ash on dry matter, on the other hand, the average content is equal to $10.51 \% \pm 2.14$. In this case, the highest content was $15.49 \%$ and the lowest was $6.28 \%$. The high content of crude ash is an indication of probable forage contamination with soil (29). In one study, it is reported that the values of ash above $14.0 \%$ on the dry matter for alfalfa hay are an indication of exogenous ash (29). Only six samples (refer to sample $n 1,8$, 24, 47, 53, and 54 in Table 1), two of which from alfalfa, showed the ash values expressed on dry matter content higher than $14 \%$. It is interesting to note that the AFB1 levels in this subset of samples $(0.0037 \pm 0.00042 \mathrm{mg} / \mathrm{kg})$ were higher $(p=0.0229)$ than that observed on samples having ash content lower than $14 \%(0.0032 \pm 0.00095 \mathrm{mg} / \mathrm{kg})$, although all samples were below the legal limits. Indeed, as listed in Table $\mathbf{1}$, the values of AFB1 content ranged from 0.0020 to $0.0077 \mathrm{mg} / \mathrm{kg}$ with an average of $0.0033 \mathrm{mg} / \mathrm{kg}$.

This study results showed that all the samples did not exceed the established limits of $0.02 \mathrm{mg} / \mathrm{kg}$ set for feed materials by Directive 2002/32/EC as amended by Commission Regulation (EU) 574/2011 (30) (Table 1). Many authors have
TABLE 1 | Storage time, moisture, ash, and aflatoxin B1 (AFB1) of hay samples.

\begin{tabular}{|c|c|c|c|c|}
\hline Sample & $\begin{array}{l}\text { Storage } \\
\text { time } \\
\text { (months) }\end{array}$ & $\begin{array}{l}\text { Moisture } \\
(\%)\end{array}$ & $\begin{array}{l}\text { Ash, on } \\
\text { dry } \\
\text { matter } \\
\text { basis (\%) }\end{array}$ & $\begin{array}{c}\text { Aflatoxin B1, } \\
\text { expressed on a } \\
\text { moisture content } \\
\text { of } 12 \%(\mathrm{mg} / \mathrm{kg} \text { ) }\end{array}$ \\
\hline 1 & 5 & 13.69 & 14.81 & 0.0038 \\
\hline 2 & 5 & 12.04 & 12.30 & 0.0036 \\
\hline 3 & 5 & 12.34 & 10.92 & 0.0031 \\
\hline 4 & 5 & 8.72 & 10.64 & 0.0034 \\
\hline 5 & 4 & 8.03 & 12.19 & 0.0031 \\
\hline 6 & 2 & 10.30 & 12.72 & 0.0034 \\
\hline 7 & 5 & 8.96 & 9.34 & 0.0026 \\
\hline 8 & 5 & 10.12 & 15.49 & 0.0037 \\
\hline 9 & 4 & 8.64 & 12.22 & 0.0028 \\
\hline 10 & 4 & 9.78 & 12.15 & 0.0027 \\
\hline 11 & 3 & 9.88 & 9.73 & 0.0031 \\
\hline 12 & 2 & 9.74 & 9.84 & 0.0026 \\
\hline 13 & 6 & 14.36 & 10.37 & 0.0077 \\
\hline 14 & 7 & 15.52 & 10.08 & 0.0037 \\
\hline 15 & 5 & 16.42 & 11.40 & 0.0034 \\
\hline 16 & 4 & 7.48 & 10.18 & 0.0031 \\
\hline 17 & 6 & 8.72 & 9.86 & n.d. \\
\hline 18 & 6 & 7.64 & 9.80 & n.d. \\
\hline 19 & 5 & 10.73 & 8.24 & n.d. \\
\hline 20 & 5 & 11.95 & 8.92 & 0.0034 \\
\hline 21 & 5 & 13.49 & 10.57 & 0.0025 \\
\hline 22 & 5 & 10.93 & 11.73 & 0.0038 \\
\hline 23 & 7 & 19.21 & 12.03 & 0.0037 \\
\hline 24 & 6 & 17.42 & 14.15 & 0.0041 \\
\hline 25 & 7 & 12.45 & 9.80 & 0.0029 \\
\hline 26 & 2 & 14.42 & 12.63 & 0.0031 \\
\hline 27 & 7 & 7.70 & 8.40 & 0.0024 \\
\hline 28 & 7 & 7.77 & 8.91 & 0.0028 \\
\hline 29 & 6 & 13.44 & 10.73 & 0.0027 \\
\hline 30 & 6 & 11.58 & 8.09 & 0.0036 \\
\hline 31 & 6 & 12.51 & 11.65 & 0.0023 \\
\hline 32 & 5 & 13.07 & 7.37 & 0.0036 \\
\hline 33 & 5 & 13.53 & 7.50 & 0.0021 \\
\hline 34 & 6 & 12.86 & 9.41 & 0.0033 \\
\hline 35 & 4 & 11.69 & 8.27 & 0.0026 \\
\hline 36 & 3 & 18.02 & 9.91 & 0.0035 \\
\hline 37 & 5 & 13.49 & 7.92 & 0.0023 \\
\hline 38 & 6 & 7.27 & 9.54 & 0.0034 \\
\hline 39 & 7 & 7.85 & 7.69 & 0.0055 \\
\hline 40 & 6 & 9.74 & 6.28 & 0.0048 \\
\hline 41 & 6 & 12.62 & 10.97 & 0.0038 \\
\hline 42 & 6 & 13.47 & 9.40 & 0.0023 \\
\hline 43 & 6 & 13.57 & 7.87 & 0.0025 \\
\hline 44 & 6 & 13.54 & 8.66 & 0.0025 \\
\hline 45 & 7 & 13.58 & 10.02 & 0.0035 \\
\hline 46 & 7 & 14.04 & 10.97 & 0.0038 \\
\hline 47 & 6 & 13.68 & 14.28 & 0.0035 \\
\hline 48 & 5 & 15.29 & 12.01 & 0.0037 \\
\hline
\end{tabular}

(Continued) 
TABLE 1 | Continued

\begin{tabular}{lcccc}
\hline Sample & $\begin{array}{c}\text { Storage } \\
\text { time } \\
\text { (months) }\end{array}$ & $\begin{array}{c}\text { Moisture } \\
\mathbf{( \% )}\end{array}$ & $\begin{array}{c}\text { Ash, on } \\
\text { dry } \\
\text { matter } \\
\text { basis (\%) }\end{array}$ & $\begin{array}{c}\text { Aflatoxin B1, } \\
\text { expressed on a } \\
\text { moisture content } \\
\text { of 12\% (mg/kg) }\end{array}$ \\
\hline 49 & 6 & 17.96 & 11.53 & 0.0031 \\
50 & 6 & 13.47 & 7.98 & 0.0035 \\
51 & 6 & 12.39 & 10.82 & 0.0033 \\
52 & 7 & 13.05 & 11.22 & 0.0027 \\
53 & 5 & 13.59 & 14.99 & 0.0029 \\
54 & 4 & 14.73 & 14.94 & 0.0039 \\
55 & 7 & 12.89 & 8.49 & 0.0020 \\
Mean & & 12.21 & 10.51 & 0.0033 \\
sd & & 2.89 & 2.14 & 0.0009 \\
Max & & 19.21 & 15.49 & 0.0077 \\
Min & & 7.27 & 6.28 & 0.0020 \\
\hline
\end{tabular}

The table summarizes the major features of the samples employed in this study. Parenthesis expresses the units for each column. Samples 17, 18, and 19 were not analyzed for the content of AFB1 and are marked as n.d.

reported concentrations that exceeded the established limits. Decastelli et al. (31) in northern Italy found that $8.1 \%$ of the feed samples analyzed were positive to confirmation analysis (AFB1), a value that was higher than the maximum allowable in the feed and the milk. In Iran, the concentration of AFB1 in the hay was higher $(10 \% ; 4 / 40)$ than the EU limit (32). Pleadin et al. (33) found $22.2 \%$ of AFB1-positive samples and detect that $12.3 \%$ of the feed samples had concentrations above the limit. In Tanzania, Mohammed et al. (34) found that $\mathrm{AFB}_{1}$ was present in $65 \%(13 / 20)$ of the feed samples and $61.53 \%$, exceeding both the Tanzania Food and Drug Authority and European commission maximum limits of $5 \mathrm{ng} / \mathrm{g}(0.005 \mathrm{mg} / \mathrm{kg})$ for complete dairy animal feed. Inversely, other studies have found a relatively high number of contaminated samples but rarely exceeding the established legal limit. In China, $42 \%$ of the samples contained AFB1 ranging from 0.05 to $3.53 \mu \mathrm{g} / \mathrm{kg}$, below the legal limit in European and Chinese $(10 \mu \mathrm{g} / \mathrm{kg}$, equivalent to $0.01 \mathrm{mg} / \mathrm{kg})$ limits (35). In Portugal, Martins et al. (36) in a 10-year study, found $37.4 \%$ positive samples with contamination ranging from 1 to $74 \mu \mathrm{g} / \mathrm{kg}$, and only $6.2 \%$ of samples exceeded the maximum limit established in Portugal $(5 \mu \mathrm{g} / \mathrm{kg}$, equivalent to $0.005 \mathrm{mg} / \mathrm{kg})$.

The climate conditions could influence mold spoilage and favorable environmental conditions are critical for the production of mycotoxin. An interesting study that evaluated the presence of mycotoxins in relation to the geographical area, reported that more than half of the specimens collected in Europe exceeded the legal limit of quantification; in the AsianPacific area, contaminations by AF were more common (37). Furthermore, the level of AFB1 in feed samples collected during the winter season was found to be higher than those collected in the summer months (38). Therefore, many explanatory variables may affect the probability of AFB1 production and worldwide scientific evidence indicate the complexity to predict the consequent actual risk for animals and humans.
The occurrence of mycotoxin in animal feed could results in the carry-over effect of AFM1 in milk at dairy farms. When dairy cattle eat feedstuffs containing AFB1, this toxin is metabolized in AFM1 and, thus, excreted in milk, representing the main concern for public health. In milk, the limit of AFM1 is 0.05 $\mu \mathrm{g} / \mathrm{kg}(7)$. The low frequency of AFM1 contamination in milk is the consequence of control of AFM1 in milk joined with the routine surveillance of AFB1 in the primary production of feeds for dairy animals. In an interesting review, Min et al. (39) underlined the great risk related to high AFM1 concentrations in raw milk in several countries. The consumption of contaminated raw or pasteurized milk can be considered a significant risk, especially for the health of infants and children since milk is the major constituent of their diet (40). In Italy, it was found that no commercial sample exceeded the limit defined at the community level for AFM1 in milk $(0.05 \mu \mathrm{g} / \mathrm{kg})(41)$. A correlation between AFs in feed and AFM1in milk has not been detected always, as reported. Blanco (42) reported that although none of the feed samples examined exceeded the EU maximum content for AFB1 in feeding stuff for dairy animals, some bulk milk samples $(n=$ 3) exceeded the maximum level for AFM1 in milk (50 ng/kg) established in EU. Monitoring of feedstuffs is a useful tool to try and minimize AF contamination of milk.

Concerning mold characterization, the results are synthesized in Table 2. A total of 33 different taxa were identified, mainly belonging to the Phylum Ascomycota and, within it, to the genera Cladosporium, Alternaria, Aspergillus, Fusarium, and Epicoccum. The Phylum Mucoromycota was represented by species belonging to the genera Rhizopus and Mucor.

The highest percentage of sample was colonized by Cladosporium cladosporioides $(n=46,84 \%)$ followed by Rhizopus stolonifer $(n=35,64 \%)$ and Alternaria alternata ( $n$ $=25,45 \%)$. Cladosporium is one of the most frequent airborne species, mainly found in the inside and outside environments of agricultural context and dairy farms, responsible for damage of sheep and cow cheese surface (forming black tight spots); moreover, Cladosporium spores are known to play a role as aeroallergens and the prolonged exposure to high spore concentrations could cause upper respiratory symptoms related to chronic allergy and asthma $(43,44)$. Rhizopus stolonifer is a typically atoxigenic post-harvest mold of fruit and vegetable, and mold spoilage occurs mainly during storage, transport, and commercialization (45). Alternaria alternata, which was rescued in a percentage of $45 \%$, is a ubiquitous, saprophytic fungus isolated in a variety of habitats, commonly in dead plant materials, and is also a plant pathogen causing disease on several crops $(46,47)$. The genus Alternaria includes some species related to the production of toxins, such as alternariol, altenuene, tenuazonic acid, and altertoxin, thus implying a serious hazard (48). In an interesting study, spices and herbs marketed in Lebanon were analyzed for Alternaria mycotoxins and found a high incidence $(89 \%)$ of sample contamination, highlighting the high susceptibility of these matrices to these potential harmful mycotoxins (49).

Considering the purposes of this study, the result of $A$. flavus as the most frequent toxigenic species isolated $(n=11,20 \%)$, deserves to be highlighted. It is the main source of AFB1, of which 
TABLE 2 | Mycological results of hay samples.

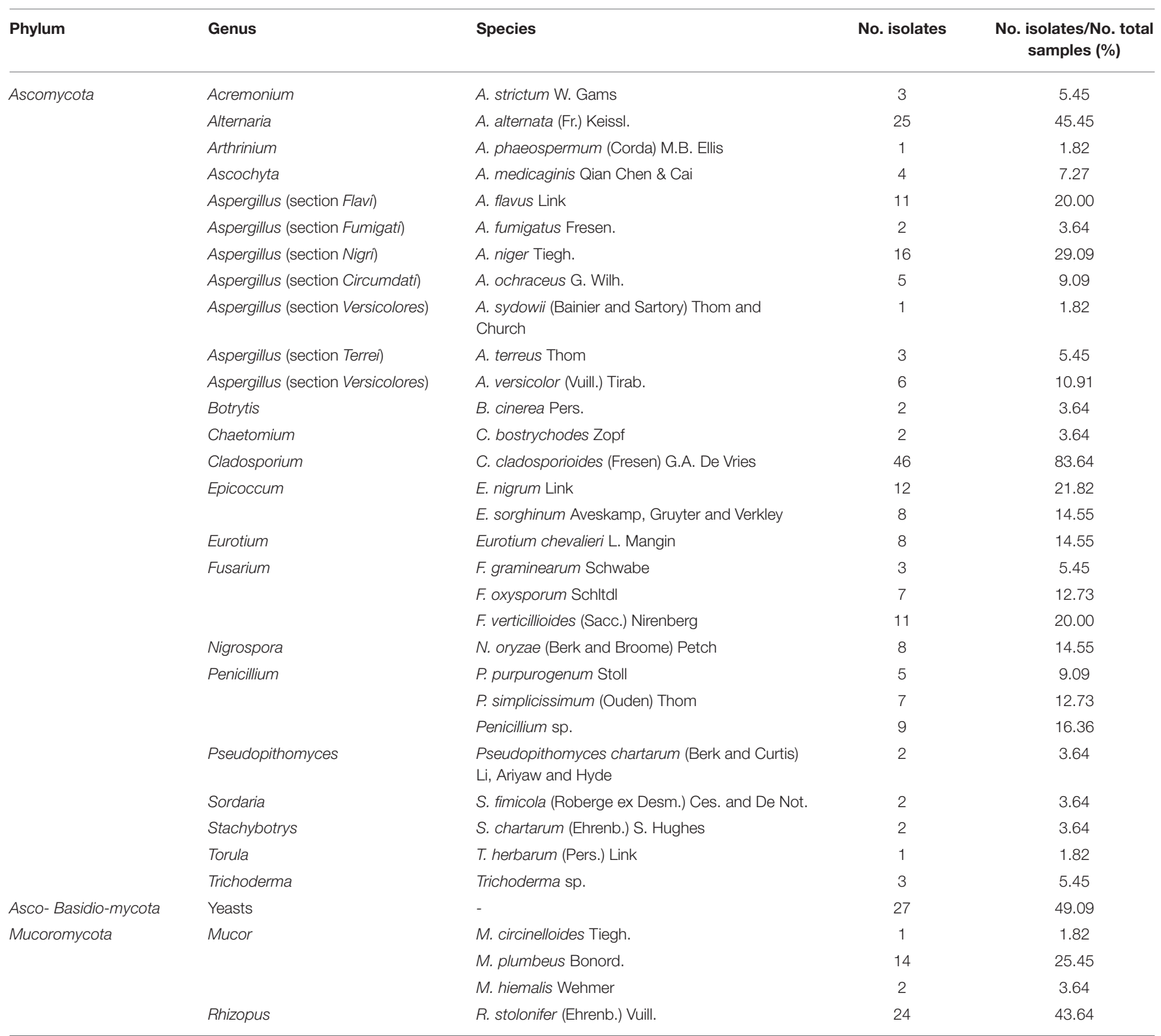

the ubiquitous growth can occur at any point in the pre- or postharvest stage, making it difficult to control the contamination (13). The dairy feed may represent suitable media for the growth and proliferation of Aspergillia. In a survey conducted in Nigeria, on 144 feed samples destined to dairy herds, $55.8 \%$ of the isolates Aspergillia were identified as A. flavus but only $12(25.0 \%)$ were identified as aflatoxigenic strains (50). In Iran on 110 samples collected in dairy farms, the most frequent isolated fungi (Aspergillus fumigatus, A. flavus, Aspergillus niger, A. parasiticus, and Aspergillus oryzae) were found in the hay samples (92\%) (51). Ghisian et al. (52), in Iran during the winter season, found that predominant fungi isolated were Aspergillus species (37.4\%) followed by Penicillium (23.7\%), Fusarium (17.5\%), Cladosporium (9.1\%), Alternaria (4.3\%), Rhizopus (3.9\%), and
Mucor species (3.4\%). A not negligible detection of Penicillium and Fusarium emerged in this study too, and some data (i.e., Fusarium verticillioides, $n=11,20 \%$; Fusarium oxysporum, $n=$ $7,13 \%$ ) could deserve future insights, still concerning a potential toxigenic risk.

Interestingly, in the current survey, none of the samples colonized by Aspergillia exceed the limit of AFB1, thus indicating that the presence in the hay of detectable fungal propagules not necessarily implies the production-and the risk-of mycotoxins. In a study performed by Granados-Chinchilla et al. (53) on 1,200 rice samples, collected from 20 states across India, was found that all the samples showed the presence of Aspergillia, predominantly represented by A. flavus ( $n=$ $1002,67.8 \%)$; these samples were positive to AFB1 but only 
$2 \%$ showed contamination above the permissible limits $(>30$ $\mu \mathrm{g} / \mathrm{kg}$ ) (assessed by Elisa). These findings are in agreement with Udom (54) that showed a low incidence of aflatoxigenic A. flavus and high incidence of AFB1, probably due to rapid depletion of the vegetative phase of the organism due to harsh environmental conditions with no significant consequence on thermostable AF. Similarly, Omeiza et al. (50), in a study carried out in 2018, reported a high percentage of positive samples for AFB1 associated with a low incident rate of aflatoxigenic strains of $A$. flavus. International data state that AF contamination of feedstuff can both lead to considerable production losses and be a great hazard for animal and human health. The current study confirmed that: hay used as feed materials for dairy cattle are naturally colonized with filamentous fungi and yeasts, often occurring in the field because of the infection of plant symbiotic fungi as phytopathogens; in well-preserved forages, the metabolic activity of molds can be greatly reduced, making it impossible to set a direct and replicable ratio between the presence of a certain species and its mycotoxin; the hay-making process, as well as the post-harvest handling and storage of these organic products, are key conditions for preventing their rapid spoilage and, consequently, for guaranteeing quality and safety to the whole productive chain. The results of this study agree with those obtained from similar studies, and confirm that random inspections of hay, by means of microbiological and/or biochemical techniques, are recommended and should be constantly performed. Especially, frequent AFB1 monitoring should be established, particularly, in hays with high moisture and crude ash content, to prevent the introduction of this major toxin into the food chain. We conclude that the quality of raw materials and good practices of storage are essential for

\section{REFERENCES}

1. Scudamore KA, Livesey CT. Occurrence and significance of mycotoxins in forage crops and silage: a review. J Sci Food Agric. (1998) 77:117. doi: 10.1002/(SICI)1097-0010(199805)77:1<1::AID-JSFA9>3.0.CO;2-4

2. Orina A, Gavrilova OP, Gagkaeva T, Burkin A, Kononenko G. The contamination of Fabaceae plants with fungi and mycotoxins. Agric Food Sci. (2020) 29:265-75. doi: 10.23986/afsci.89171

3. Kononenko G, Burkin A, Gavrilova O, Gagkaeva T. Fungal species and multiple mycotoxin contamination of cultivated forage crops. Agric Food Sci. (2015) 24:323-30. doi: 10.23986/afsci.52313

4. Ames JP, Neres MA, Castagnara DD, Mufatto LM, Ducati C, Jobim CC, et al. Dry matter production, chemical composition, dry matter digestibility and occurrence of fungi in Bermuda grass hay (Cynodon dactylon) under different fertilization systems or associated with pea plantings in winter. Int J Agric Nat Resour. (2014) 41:163-74. doi: 10.4067/S0718-16202014000200003

5. Changwa R, De Boevre $M$, De Saeger S, Njobeh PB. Feed-based multi-mycotoxin occurrence in smallholder dairy farming systems of South Africa: the case of limpopo and free state. Toxins. (2021) 13:166. doi: 10.3390/toxins13020166

6. Gallo A, Giuberti G, Frisvad JC, Bertuzzi T, Nielsen KF. Review on mycotoxin issues in ruminants: Occurrence in forages, effects of mycotoxin ingestion on health status and animal performance and practical strategies to counteract their negative effects. Toxins. (2015) 7:3057-111. doi: 10.3390/toxins7083057

7. Union E. Commission Regulation (EC) No 165/2010 of 26 February 2010, amending Regulation (EC) No 1881/2006 setting maximum levels for certain contaminants in foodstuffs as regards aflatoxins. Off J Eur Union. (2010) 50:8-12. (2010) 50:8-12. Availabe online at: http://data.europa.eu/eli/ reg/2006/1881/oj the prevention of spoilage and mycotoxin spread and, thus, for human and animal health. Finally, since this toxigenic matter may vary according to the geographical area and climatic features, we propose this first analysis performed in Calabria as a reliable starting point for a more accurate and proven strategy of territorial assessment.

\section{DATA AVAILABILITY STATEMENT}

The raw data supporting the conclusions of this article will be made available by the authors, without undue reservation.

\section{AUTHOR CONTRIBUTIONS}

$\mathrm{NC}$ and CC contributed to the conception and design of the study. VM, CC, and MR contributed to methodology. AS organized the database. VM performed the statistical analysis. VM and AS performed the validation. CC, AS, and MR performed the analysis. MR performed the mycological investigation. VM contributed to data curation. CC and $\mathrm{NC}$ wrote the first draft of the manuscript. BT and CP wrote sections of the manuscript. NC, VM, and DB contributed to supervision of the project. VM and DB contributed to resources acquisition. All authors have read and contributed to writing, editing the final version of the manuscript, and agreed to the published version of the manuscript.

\section{ACKNOWLEDGMENTS}

The authors kindly thank Valter Mondella for technical support and hay collection.
8. Wacoo AP, Wendiro D, Vuzi PC, Hawumba JF. Methods for detection of aflatoxins in agricultural food crops. J Appl Chem. (2014) 2014:115. doi: 10.1155/2014/706291

9. Cheung CT, DeLisio MP, Rosenberg JJ, Tsai R, Kagiwada R, Rutledge DB, et al. Single chip two-stage W-band grid amplifier. IEEE MTT-S Int Microw Symp Dig. (2004) 1:79-82. doi: 10.1109/MWSYM.2004.1335805

10. de Oliveira CAF, Corassin CH. Aflatoxins. Mycotoxins their implic food safety. Food Med. (2014) 1971:6-19. doi: 10.4155/ebo.13.468

11. Higginson J, DeVita VT. IARC monographs on the evaluation of carcinogenic risk of chemicals to humans. Am Ind Hyg Assoc J. (1980) 41:A26.

12. Mahato DK, Lee KE, Kamle M, Devi S, Dewangan KN, Kumar P, et al. Aflatoxins in food and feed: an overview on prevalence, detection and control strategies. Front Microbiol. (2019) 10:1-10. doi: 10.3389/fmicb.2019. 02266

13. Rushing BR, Selim MI. Aflatoxin B1: a review on metabolism, toxicity, occurrence in food, occupational exposure, and detoxification methods. Food Chem Toxicol. (2019) 124:81-100. doi: 10.1016/j.fct.2018.11.047

14. Akande KE, Abubakar MM, Adegbola TA, Bogoro SE. Nutritional and health implications of mycotoxins in animal feeds: a review. Pakistan J Nutr. (2006) 5:398-403. doi: 10.3923/pjn.2006.398.403

15. European Parliament and the Council of the EU. Directive of the European parliament and of the council of 7 May 2002 on undesirable substances in animal feed 2002/32. Off J Eur Communities. (2002) 140:1-15. Availabe online at: http://data.europa.eu/eli/dir/2002/32/oj

16. EUR-Lex-L_2011_159_TOC - EN - EUR-Lex European Commission.

17. Al-Mentafji HN. Official Methods of Analysis. Rockville: AOAC International (2006).

18. Harris JL. Modified method for fungal slide culture. J Clin Microbiol. (1986) 24:460-1. doi: $10.1128 / \mathrm{jcm} .24 .3 .460-461.1986$ 
19. Weller DM, Raaijmakers JM, Gardener BBM, Thomashow LS. Microbial poulation responsible for specific soil suppressiveness to plant pathogens. Ann Rev Phytopath. (2002) 40:309-348. doi: 10.1146/annurev.phyto.40.030402.110010

20. Gams W. More dematiaceous hyphomycetes. Netherlands J Plant Pathol. (1977) 83:90. doi: 10.1007/BF01989814

21. Sutton BC. The Coelomycetes: Fungi Imperfecti with Pycnidia, Acervuli and Stromata. Kew: Commonwealth Mycological Institute (1980). p. 696.

22. Klich MA. Identification of Common Aspergillus Species. Utrecht: Centraalbureau voor Schimmelcultures (2002). p. 116.

23. Domsch KH, Gams W, Anderson T-H. Compendium of Soil Fungi. Eching: IHW-Verlag (2007).

24. Moreno Romo MA, del Carmen Ramos Cartagena M, Rodriguez Ferri EF, Suárez Fernández G. Minimal moisture content for growth and aflatoxin production by aspergillus parasiticus in mixed feeds. Mycopathologia. (1986) 95:145-8. doi: 10.1007/BF00437118

25. Wittenberg KM, Undi M, Bossuyt C. Establishing a feed value for moulded hay. Anim Feed Sci Technol. (1996) 60:30110. doi: 10.1016/0377-8401(96)00985-6

26. Gregory PH, Lacey ME, Festenstein GN, Skinner FA, Station EE. Microbial and biochemical changes during the moulding of hay. J Gen Microbiol. (1963) 33:147-74. doi: 10.1099/00221287-33-1-147

27. Rotz CA, Muck RE. Changes in forage quality during harvest and storage. In: Fahey GC, editors. Forage Quality, Evaluation, and Utilization. Madison: American Society of Agronomy (2015). p. 828-68.

28. Martinson K, Coblentz W, Sheaffer C. The effect of harvest moisture and bale wrapping on forage quality, temperature, and mold in orchardgrass hay. $J$ Equine Vet Sci. (2011) 31:711-6. doi: 10.1016/j.jevs.2011.05.003

29. Scholtz GDJ, van der Merwe HJ, Tylutki TP. The nutritive value of South African Medicago sativa L. hay. South African J Anim Sci. (2009) 39(Suppl. 1):179-82. doi: 10.4314/sajas.v39i1.61269

30. CVM, FDA. CPG Sec. 683.100 Action Levels for Aflatoxins in Animal Food. (2019). Available online at: https://www.fda.gov/ICECI/ComplianceManuals/ CompliancePolicyGuidanceManual/default.htm (accesed August 4 2019).

31. Decastelli L, Lai J, Gramaglia M, Nachtmann C, Oldano F, Ru M, et al. A X atoxins occurrence in milk and feed in Northern Italy during 2004-2005. Food control. (2007) 18:1263-6. doi: 10.1016/j.foodcont.2006.08.006

32. Bahrami R, Shahbazi Y, Nikousefat Z. Occurrence and seasonal variation of aflatoxin in dairy cow feed with estimation of aflatoxin M 1 in milk from Iran. Food Agric Immunol. (2016) 27:388-400. doi: 10.1080/09540105.2015.1109613

33. Pleadin J, Vuli A, Skrivanko M. Annual and regional variations of a $\mathrm{fl}$ atoxin B 1 levels seen in grains and feed coming from Croatian dairy farms over a 5-year period b. Food control. (2015) 47:2215. doi: 10.1016/j.foodcont.2014.07.017

34. Mohammed S, Munissi JJE, Nyandoro SS. Aflatoxin M1 in raw milk and aflatoxin B1 in feed from household cows in Singida, Tanzania. Food Addit Contam Part B, Surveill. (2016) 9:85-90. doi: 10.1080/19393210.2015.1137361

35. Han RW, Zheng N, Wang JQ, Zhen YP. Survey of a flatoxin in dairy cow feed and raw milk in China. Food control. (2013) 34:359. doi: 10.1016/j.foodcont.2013.04.008

36. Martins HM, Manuela M, Guerra M. Occurrence of aflatoxin B 1 in dairy cow's feed over 10 years in Portugal. Rev Iberoam Micol. (2007) 24:69-71. doi: 10.1016/j.foodcont.2018.05.022

37. Binder EM, Tan LM, Chin LJ, Handl J, Richard J. Worldwide occurrence of mycotoxins in commodities, feeds and feed ingredients. Anim Feed Sci Technol. (2007) 137:265-82. doi: 10.1016/j.anifeedsci.2007. 06.005

38. Ismail A, Akhtar SE, Park S. Seasonal variation of aflatoxin B 1 content in dairy feed. J Animal Feed Sci. (2017) 26:33-37. doi: 10.22358/jafs/69008/2017

39. Min L, Li D, Tong X, Sun H, Chen W, Wang G, et al. The challenges of global occurrence of aflatoxin M1 contamination and the reduction of aflatoxin M1 in milk over the past decade. Food Control. (2020) 117:107352. doi: 10.1016/j.foodcont.2020.107352

40. Daou R, Afif C, Joubrane K, Khabbaz LR, Maroun R, Ismail $A$, et al. Occurrence of aflatoxin M1 in raw, pasteurized, UHT cows' milk, and dairy products in Lebanon. Food Control. (2020) 111:107055. doi: 10.1016/j.foodcont.2019.107055
41. Armorini S, Altafini A, Zaghini A, Roncada P. Occurrence of aflatoxin M1 in conventional and organic milk offered for sale in Italy. Mycotoxin Res. (2016) 32:237-46. doi: 10.1007/s12550-016-0256-8

42. Rodríguez-Blanco M, Ramos AJ, Prim M, Sanchis V, Marín S. Usefulness of the analytical control of aflatoxins in feedstuffs for dairy cows for the prevention of aflatoxin M1 in milk. Mycotoxin Res. (2020) 36:1122. doi: 10.1007/s12550-019-00362-y

43. Messini A, Buccioni A, Minieri S, Mannelli F, Mugnai L, Comparini C, et al. Effect of chestnut tannin extract (Castanea sativa Miller) on the proliferation of Cladosporium cladosporioides on sheep cheese rind during the ripening. Int Dairy J. (2017) 66:6-12. doi: 10.1016/j.idairyj.2016.10.012

44. Zeng Q-Y, Westermark S-O, Rasmuson-Lestander A, Wang X-R. Detection and quantification of Cladosporium in aerosols by real-time PCR. J Environ Monit. (2006) 8:153-60. doi: 10.1039/B509515H

45. Zhang $\mathrm{H}$, Wang L, Zheng $\mathrm{X}$. Dong Y. Effect of yeast antagonist in combination with heat treatment on postharvest blue mold decay and Rhizopus decay of peaches. Int J Food Microbiol. (2007) 115:538. doi: 10.1016/j.ijfoodmicro.2006.10.002

46. Leuven KU. Alternaria spp.: from general saprophyte to specific parasite. $\mathrm{Mol}$ Pl Pat. (2003) 4:225-36. doi: 10.1046/j.1364-3703.2003.00173.x

47. Ostry V. Alternaria mycotoxins: an overview of chemical characterization, producers, toxicity, analysis and occurrence in foodstuffs. World Mycotoxin J. (2008) 1:175-88. doi: 10.3920/WMJ2008.x013

48. EFSA Panel on Contaminants in the Food Chain. Scientific opinion on the risks for animal and public health related to the presence of Alternaria toxins in feed and food. Eur Food Saf. (2011) 9:1-97. doi: 10.2903/j.efsa.2011.2407

49. Gambacorta L, El Darra N, Fakhoury R, Logrieco AF, Solfrizzo M. Incidence and levels of Alternaria mycotoxins in spices and herbs produced worldwide and commercialized in Lebanon. Food Control. (2019) 106:106724. doi: 10.1016/j.foodcont.2019.106724

50. Omeiza GK, Kabir J, Kwaga JKP, Kwanashie CN, Mwanza M, Ngoma L. A risk assessment study of the occurrence and distribution of a $\mathrm{fl}$ atoxigenic Aspergillus flavus and a flatoxin B1 in dairy cattle feeds in a central northern state, Nigeria. Toxicol Rep. (2018) 5:846-56. doi: 10.1016/j.toxrep.2018.08.011

51. Davari E, Mohsenzadeh M, Mohammadi G, Rezaeian-Doloei R. Characterization of aflatoxigenic Aspergillus flavus and A. parasiticus strain isolates from animal feedstuffs in northeastern Iran. Iran J Vet Res. (2015) 16:150-5.

52. Ghiasian SA, Maghsood AH. Occurrence of aflatoxigenic fungi in cow feeds during the summer and winter season in Hamadan, Iran. Afr J Microbiol Res. (2011) 5:516-21.

53. Granados-chinchilla F, Molina A, Chavarría G, Alfaro-cascante M, Bogantes-ledezma D, Murillo-williams A, et al. A flatoxins occurrence through the food chain in Costa Rica : applying the One Health approach to mycotoxin surveillance. Food Control. (2017) 82:217-26. doi: 10.1016/j.foodcont.2017.06.023

54. Udom IE, Ezekiel CN, Fapohunda SO, Okoye ZSC, Kalu CA. Adv JV. Incidence of aspergillus section flavi and concentration of aflatoxin in feed concentrates for cattle in Jos, Nigeria. J Vet Adv. (2012) 2:39-46.

Conflict of Interest: The authors declare that the research was conducted in the absence of any commercial or financial relationships that could be construed as a potential conflict of interest.

Publisher's Note: All claims expressed in this article are solely those of the authors and do not necessarily represent those of their affiliated organizations, or those of the publisher, the editors and the reviewers. Any product that may be evaluated in this article, or claim that may be made by its manufacturer, is not guaranteed or endorsed by the publisher.

Copyright (C) 2021 Ceniti, Costanzo, Spina, Rodolfi, Tilocca, Piras, Britti and Morittu. This is an open-access article distributed under the terms of the Creative Commons Attribution License (CC BY). The use, distribution or reproduction in other forums is permitted, provided the original author(s) and the copyright owner(s) are credited and that the original publication in this journal is cited, in accordance with accepted academic practice. No use, distribution or reproduction is permitted which does not comply with these terms. 